\title{
Antitussive Effect of RU-20201--Central and Peripheral Actions
}

\author{
Saizo YANAURA, Hideaki FUJIKURA, Tomokazu HOSOKAWA, \\ Harumi KITAGAWA, Junzo KAMEI and Miwa MISAWA
}

Department of Pharmacology, School of Pharmacy, Hoshi University, Ebara, Shinagawa-ku, Tokyo 142, Japan

Accepted November 2, 1983

\begin{abstract}
The antitussive effect of the new compound 1,2, 3, 4a, 9b-hexahydro-8. 9b-dimethyl-4-[3-(4-methyl-piperazine-1-yl) propionamide] dibenzofuran-3-one dihydrochloride (RU-20201) was investigated in dogs and guinea pigs, including its sites of action. The antitussive effect of RU-20201 was about $1 / 10$ as potent as that of codeine phosphate in dogs with the puncture electrode-induced cough (PEC) method and about $1 / 12$ and $1 / 4$ as potent as that of codeine phosphate in guinea pigs with the PEC and chemical stimulation methods, respectively. When $\mathrm{RU}-20201$ was administered in a dose range of 1 to $10 \mathrm{mg}$ into the vertebral artery toward the brain in lightly anesthetized dogs, no antitussive effect was observed against the coughing elicited by electrical stimulation of the central cut end of the superior laryngeal nerve. However, a stimulative effect on respiration, especially on respiratory rate occurred. The peripheral effect of RU-20201 on the cough was investigated using the in situ upper trachea perfusion preparation which allows a direct drug administration to the local site around the tracheal mucosa, this site being electrically stimulated to induce coughing. A close i.a. infusion of RU-20201 in doses of 1 and $3 \mathrm{mg} / \mathrm{min}$ into the tracheal vascular bed for $5 \mathrm{~min}$ inhibited the cough response elicited by mucosal stimulation. The above findings suggest that RU-20201 has a significant antitussive activity, the site of action being probably, at least, at the cough receptor level.
\end{abstract}

1. 2. 3, 4, 4a, 9b-Hexahydro-8, 9bdimethyl-4-[3-(4-methyl-piperazine-1-yl) propionamide] dibenzofuran-3-one dihydrochloride (RU-20201) (Fig. 1) is an antitussive agent originally found from dibenzofuran derivatives by Matharu et al. (1). They reported that $\mathrm{RU}-20201$ possesses an antitussive effect as potent as that of codeine phosphate in guinea pigs when administered orally. Korpas et al. (2) also demonstrated its antitussive effect in cats when given by inhalation, and Pickering and James (3)

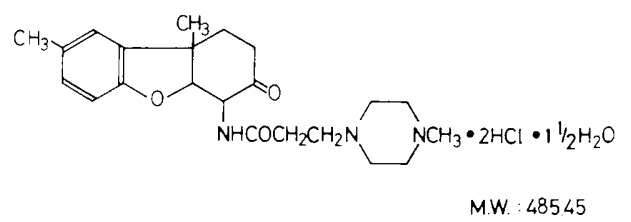

Fig. 1. Chemical structure of RU-20201. demonstrated the effect in guinea pigs and rabbits when given orally and by inhalation.

Codeine phosphate, widely used as an antitussive drug, has an inhibitory effect on respiration as well as on cough (4). On the other hand, dextromethorphan, a nonnarcotic antitussive agent, does not inhibit respiration, but rather stimulates it (5). Antitussive agents which produce no inhibitory effect or rather produce a stimulatory effect on respiration are clinically preferred. Korpas et al. (2) and Pickering and James (3) considered that RU-20201 exerts an antitussive effect through a peripheral mechanism, although no sufficient experimental evidence has been available to support this.

In the present study, the antitussive and respiratory effects of $\mathrm{RU}-20201$ were investigated in dogs and guinea pigs, being compared with results obtained for codeine 
phosphate. Whether the site of action of its antitussive effect is on the centrai level or peripheral level was also studied using methods devised by the authors.

\section{Materials and Methods}

\section{1) Antitussive effect in the dog}

The puncture electrode-induced cough (PEC) method previously described (6) was used with a partial modification. Unanesthetized and unrestrained male mongrel dogs weighing 9-15 kg were used. After the trachea caudal to the thyroid cartilage of the dog was palpated, a stimulation electrode was inserted into the trachea through a guiding cannula (stainless steel needle for s.c., size 18, Termo) and advanced to the bifurcatio tracheae. As the electrode, a stainless steel wire $(0.2 \mathrm{~mm}$ in diameter and $18 \mathrm{~cm}$ in length) coated with a cashew resin for insulation was used. Before use, the insulating layer was removed from the tips of either side of the electrode over a length of $2-3 \mathrm{~cm}$, so that electricity could be transferred. This modification done in the present study ensured a more tight insulation and easier preparation, compared to the conventional method in which a stainless steel wire is wrapped with thin polyvinyl film. This cashew-coated electrode was sheathed with a stainless steel pipe $(10 \mathrm{~cm}$ in length and $0.8 \mathrm{~mm}$ in outer diameter) and fixed with an adhesive substance. Alonalpha, at either end of the pipe. The tip that should be inserted into the trachea was bent at an angle of approximately $120^{\circ}$ so that it easily had contact with the mucous membrane of the trachea. A stainless steel needle placed into a subcutaneous site of the back was used as an indifferent electrode. For inducing the cough reflex, square-wave negative pulses $(20 \mathrm{~Hz}, 1 \mathrm{msec}, 6-8 \mathrm{~V})$ were applied for $10 \mathrm{sec}$. When coughing was induced too excessively, the puncture electrode was then drawn towards the larynx so that coughing occurred 5 to 9 times per stimulus. Prior to drug administration, electrical stimulations were given at an interval of $10 \mathrm{~min}$ until almost the same number of coughs could be evoked by each of three consecutive stimulations, from which an average pre-drug control value was calculated. Sessions of stimulations for inducing coughs were given $5,15,30$, 45, 60 and 90 min after either RU-20201 or codeine phosphate (as a reference drug) was administered i.v. into the cephalic vein. The antitussive effect was evaluated as an inhibitory ratio in terms of the percent reduction in the number of coughings compared to the average pre-drug control value.

\section{2) Antitussive effect in the guinea pig}

Male Hartley guinea pigs weighing 350$450 \mathrm{~g}$ were used. Chemical stimulation was given according to the method of Takagi et al. (7), and electrical stimulation was according to the method of Yanaura et al. (8). Both tests were slightly modified for the purpose of the present experiment.

a) Chemical stimulation $\left(\mathrm{SO}_{2}\right)$ method: In the method of Takagi et al., sulfur dioxide gas for inducing coughs is obtained by adding conc. sulfuric acid to the saturated solution of sodium bisulfite. Iristead, we used a gas cylinder containing highly purified liquid sulfur dioxide to simplify the method. The test apparatus used is shown in Fig. 2. The sulfur dioxide gas detector $(A)$, desiccator (C) and gas cylinder (D) were connected to each other with silicone tubes. The cock (b) was first closed, and the pressure regulator gauge (c) was set at a given position so that sulfur dioxide gas at a given pressure entered the silicone tube located between (b) and (c). The valve (d) was then closed in order to confine the gas in the silicone tube. The cock (b) was then opened to introduce the confined gas into the desiccator. The air pump (B) was used to make a uniform

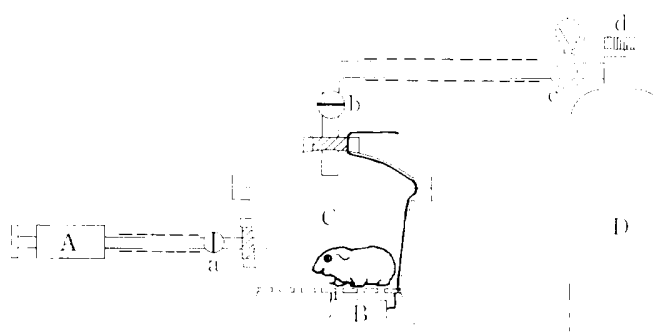

Fig. 2. Apparatus for the chemical stimulation method used in this study. A: Sulfur dioxide gas detector, B: Air pump, C: Desiccator, D: Sulfur dioxide gas cylinder, a, b: Glass cock with stopper, c: Pressure regulator gauge, $d$ : Gas cylinder valve. 
concentration of sulfur dioxide gas throughout the desiccator. The cock (a) was opened in case of need to check the concentration of sulfur dioxide gas in the desiccator with the gas detector. A gas concentration at 600 to 800 ppm was adequate to evoke coughing. A guinea pig was placed on the perforated plate inside the dessicator. Sulfur dioxide gas was then introduced into the desiccator according to the method outlined above. After one-minute exposure to the gas, the animal was taken out and placed in a cage. Observation was made for 5 min to check if the animal was coughing or not. Animals which coughed twice or more during $5 \mathrm{~min}$ in a preliminary test were used in this experiment. The exposure was repeated $15 \mathrm{~min}$ before (pre-drug control) and 15 and $30 \mathrm{~min}$ after drug administration. When no cough occurred in either of the exposures given 15 and $30 \mathrm{~min}$ after drug administration, the drug was regarded as effective. ED50 was calculated with the up and down method of Brownlee et al. (9).

b) PEC method: Electrical stimulation was given to guinea pigs as mentioned in the previous paper (7). Unanesthetized guinea pigs were fixed in a supine position. A puncture electrode was introduced into the trachea through a guiding cannula, the tip of the electrode being placed near the bifurcatio tracheae. For inducing the cough reflex, square-wave pulses $(40 \mathrm{~Hz}, 1 \mathrm{msec}$, $2 \mathrm{~V}$ ) were applied for $5 \mathrm{sec}$. When no coughing occurred. stimulation was added again at an interval of $5 \mathrm{sec}$. Four sessions of stimulation to induce the cough reflex were given: twice before drug administration and twice (15 and $30 \mathrm{~min}$ ) after drug administration. The effects of drugs were evaluated in the same manner as in the case of the chemical stimulation method.

3) Effect on cough reflex and respiration when administered into the vertebral artery

Male mongrel dogs weighing $9-15 \mathrm{~kg}$ anesthetized with pentobarbital $\mathrm{Na}(30 \mathrm{mg} /$ $\mathrm{kg}$ i.v.) were used in the experiment for determining the central effect of RU-20201. The test method used was described in the previous paper (10). The drug solution was injected into the vertebral artery at a site $5 \mathrm{~cm}$ above the clavicle towards the brain.
Sessions of electrical stimulation for inducing the cough reflex were given twice at an interval of $5 \mathrm{~min}$ before drug administration and were also given $1,3,5,10,15$ and 30 min after drug administration.

\section{4) Effect on the cough receptor site}

The in situ canine upper trachea perfusion preparation (11) was used. Electrical stimulation was given to induce the cough reflex with a silver disc electrode placed on the upper tracheal mucosa where drug perfusion was made. For inducing the cough reflex, square-wave pulses $(20 \mathrm{~Hz}, 1 \mathrm{msec}, 8-10 \mathrm{~V})$ were applied for 10 sec. RU-20201 or procaine hydrochloride was infused with an infusion pump (Natsume, $\mathrm{KN}$-202) for $5 \mathrm{~min}$ at a rate of $0.04 \mathrm{ml} / \mathrm{min}$ via a rubber tube into the perfused cranial thyroid artery. Stimulation was repeated 1,3 and $5 \mathrm{~min}$ after the start of drug infusion and $3,5,10$, 15, 30, 45 and $60 \mathrm{~min}$ after the cessation of infusion. The effect of drug was evaluated with the same criteria as in the experiment in which the antitussive effect of i.v. administration of drugs was investigated in the dog (as described above).

\section{5) Drugs}

RU-20201 (Roussel Uclaf), codeine phosphate (Sankyo) and procaine hydrochloride (Sanko) were used. All drugs were dissolved in physiological saline before use. Doses are shown in terms of base quantity.

\section{Results}

1) Antitussive effects in the dog: The antitussive effect of RU-20201 in dogs is shown in Fig. 3, and that of codeine phosphate is shown in Fig. 4. Almost no antitussive effect was observed with $10 \mathrm{mg} / \mathrm{kg}$ of RU-20201. With 20 and $30 \mathrm{mg} / \mathrm{kg}$. however, the number of coughs evoked was reduced 5 min after each administration by about $50 \%$ and $90 \%$, respectively $(P<0.01)$. When $30 \mathrm{mg} / \mathrm{kg}$ of RU-20201 was used, the antitussive effect lasted for $45 \mathrm{~min}$ or more after administration. On the other hand, 1 and $3 \mathrm{mg} / \mathrm{kg}$ of codeine phosphate showed a significant antitussive effect $(P<0.05)$ which lasted for about $60 \mathrm{~min}$. The potency of RU20201 was found to be between one tenth and one twentieth of that of codeine phosphate in terms of cough-inhibitory ratio 


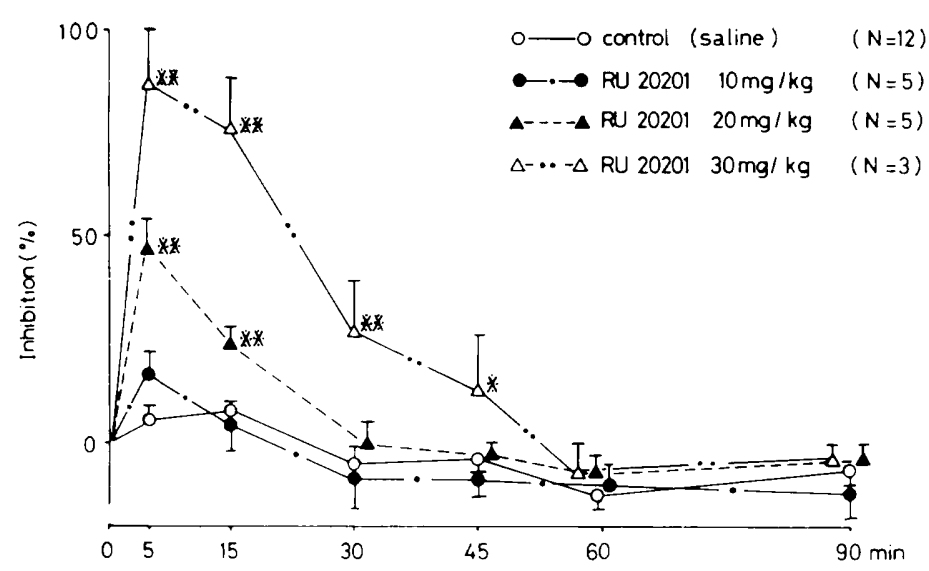

Fig. 3. The antitussive effect of RU-20201 (i.v.) on electrically induced coughs in conscious dogs. The inhibition (\%) represents that of cough frequency per stimulus. Each point is the mean value with S.E. $(N=5-12)$. Significant difference at ${ }^{*} P<0.05$ and ${ }^{* *} P<0.01$ vs. the saline group.

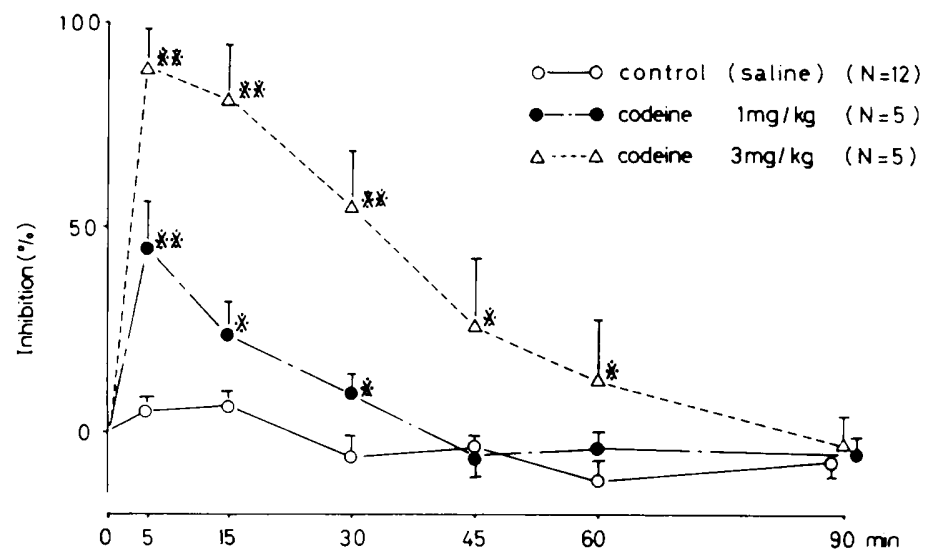

Fig. 4. The antitussive effect of codeine (i.v.) on electrically induced coughs in conscious dogs. Other explanations are as in Fig. 3.

calculated 5 min after each administration.

2) Antitussive effects in the guinea pig: The results of the chemical stimulation method are shown in Table 1a. The 50\% antitussive dose of RU-20201 was $66.1 \mathrm{mg} /$ $\mathrm{kg}$ i.p., and that of codeine phosphate was $18.2 \mathrm{mg} / \mathrm{kg}$ i.p. The potency of RU-20201 was found to be about one fourth that of codeine phosphate. The results of the electrical stimulation method are shown in Table $1 \mathrm{~b}$. The $50 \%$ antitussive dose of RU20201 was $119.2 \mathrm{mg} / \mathrm{kg}$ i.p., and that of codeine phosphate was $10.0 \mathrm{mg} / \mathrm{kg}$ i.p. In this case, the potency of RU-20201 was found to be about $1 / 12$ that of codeine phosphate.

3) Effect on cough reflex and respiration when administered into the vertebral artery: The number of coughs (N.C.) and the amplitude of cough (A.C.) were used as indices of the cough reflex. When codeine phosphate was administered via the vertebral artery. N.C. decreased dose-dependently (Fig. 5). When $1.0 \mathrm{mg}$ of the drug was given, N.C. was inhibited by a maximum of $75 \%(P<0.01)$, and A.C. was inhibited by a maximum of $60 \%(P<0.05)$. The inhibitions of N.C. and A.C. lasted for at least $15 \mathrm{~min}$ after administration. In the case of RU-20201 injected into the vertebral artery, almost no 
Table 1. Fifty percent antitussive doses (AtD50s) of RU-20201 and codeine: a) with the chemical stimulation $\left(\mathrm{SO}_{2}\right)$ method and b) with the puncture electrode-induced cough (PEC) method in conscious guinea pigs

a)

\begin{tabular}{lc}
\hline Drug & AtD50 $(\mathrm{mg} / \mathrm{kg})$ \\
\hline RU -20201 & 66.1 \\
Codeine & 18.2 \\
\hline
\end{tabular}

b)

\begin{tabular}{ccc}
\hline Drug & AtD50 $(\mathrm{mg} / \mathrm{kg})$ \\
\hline RU 20201 & 119.2 \\
Codeine & 10.0 \\
\hline
\end{tabular}

Drugs were administered i.p. Each value represents the average value for two up and down experiments.

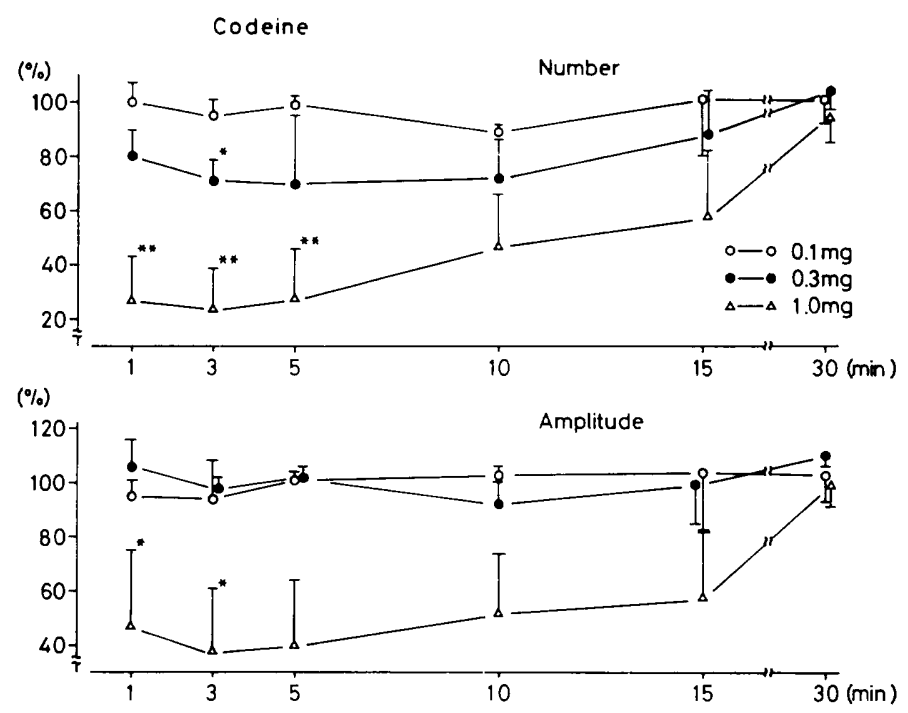

Fig. 5. The effect of codeine administered intravertebroarterially on the cough reflex induced by electrical stimulation given to the central cut end of the superior laryngeal nerve in dogs. Each point represents the mean percent change with S.E. $\left(N=3-6,{ }^{*} P<0.05\right.$ and ${ }^{* *} P<0.01$ vs. the control).

change was observed in both parameters in a dose range of 1.0 to $10.0 \mathrm{mg}$ (Fig. 6).

Respiratory rate (R.R.). respiratory amplitude (R.A.) and respiratory volume (R.V.) were used as indices of respiration. in the case of codeine phosphate, no significant change in R.A. was observed for any of the doses of $0.1,0.3$ and $1.0 \mathrm{mg}$ (Fig. 7). When 0.3 and $1.0 \mathrm{mg}$ of the drug were used, however, $20 \%$ inhibition was observed both in R.R. and R.V. In the case of P.U-
20201, no significant change in R.A. was observed for any of the following doses: 1.0 , 3.0 and $10.0 \mathrm{mg}$ (Fig. 8). When $10.0 \mathrm{mg}$ of RU-20201 was injected, however, it was observed that R.R. increased by about $40 \%$ $(P<0.05)$ and R.V. by about $45 \%$. Neither RU-20201 nor codeine phosphate affected systemic blood pressure at the doses used in this study. The results of the experiment with the drugs administered into the vertebral artery are summarized in Table 2. 

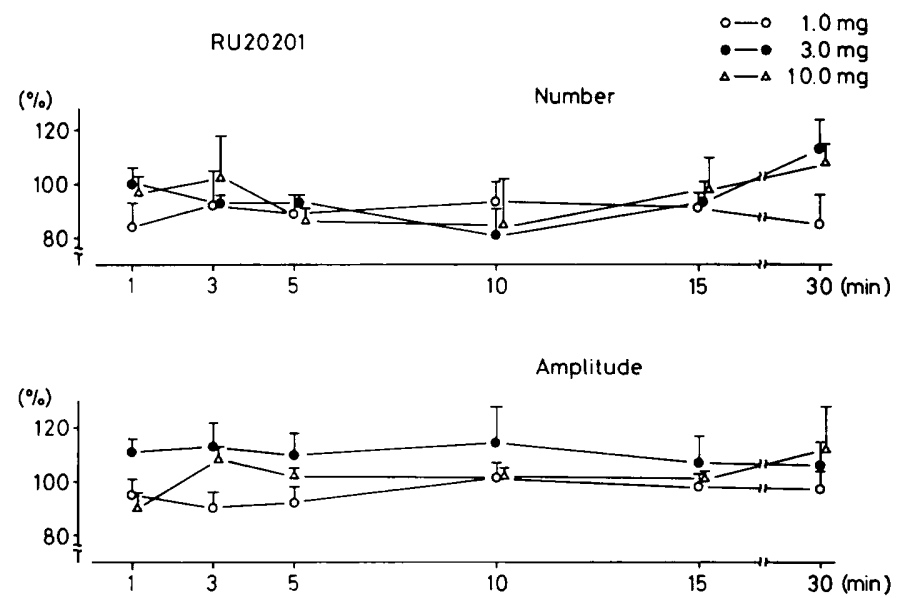

Fig. 6. The effect of RU-20201 administered intravertebroarterially on the cough reflex induced by electrical stimulation given to the central cut end of the superior laryngeal nerve in dogs. Each point represents the mean percent change with S.E. $(N=3-6)$.

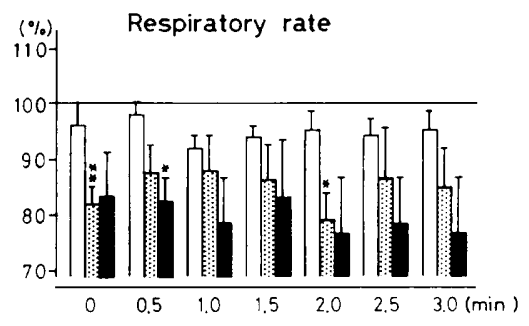

\section{Codeine}
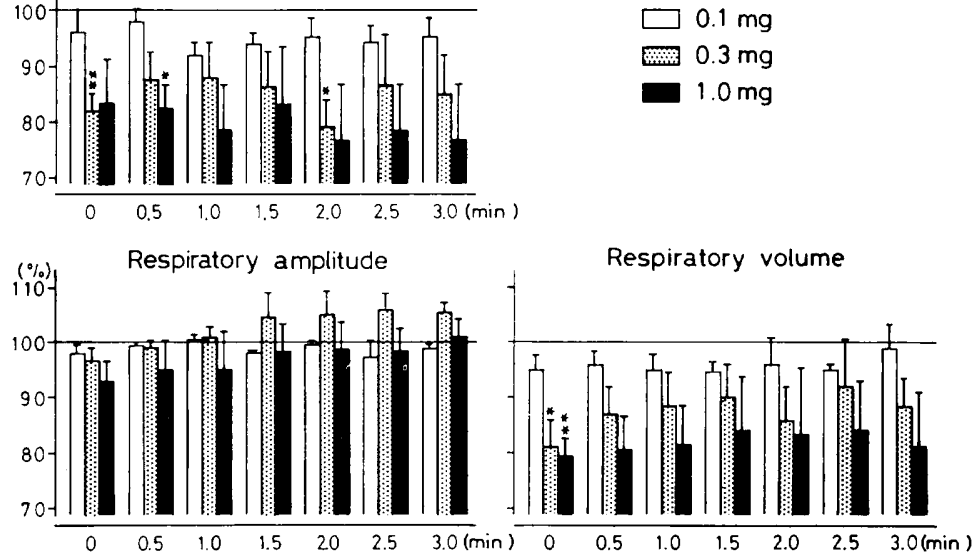

Fig. 7. The effect of codeine administered intravertebroarterially on respiration in dogs. Graphs show changes in rate, amplitude and volume of respiration for $3 \mathrm{~min}$ after drug administration. Each column represents the mean percent change with S.E. $\left(N=3-8,{ }^{*} P<0.05\right.$ and ${ }^{*} P<0.01$ vs. the control).

4) Effect on the cough receptor site: When RU-20201 (1 $\mathrm{mg} / \mathrm{min}$ ) was infused for $5 \mathrm{~min}$ into the cranial thyroid artery. about $30 \%$ cough inhibition was observed $(P<0.05)$. The inhibitory effect lasted for 5-30 $\mathrm{min}$ after the cessation of infusion. When $3 \mathrm{mg} / \mathrm{min}$ of RU-20201 was infused, about $40 \%$ cough inhibition was observed $(P<0.05) 3 \mathrm{~min}$ after the cessation of administration (Fig. 9a). When $3 \mathrm{mg} / \mathrm{min}$ of procaine was infused, a maximum of $80 \%$ cough inhibition $(P<0.05)$ was seen (Fig. $9 b)$. The inhibitory effect lasted for 15-30 min after the cessation of infusion.

\section{Discussion}

The antitussive effect of RU-20201 in guinea pigs has already been demonstrated 


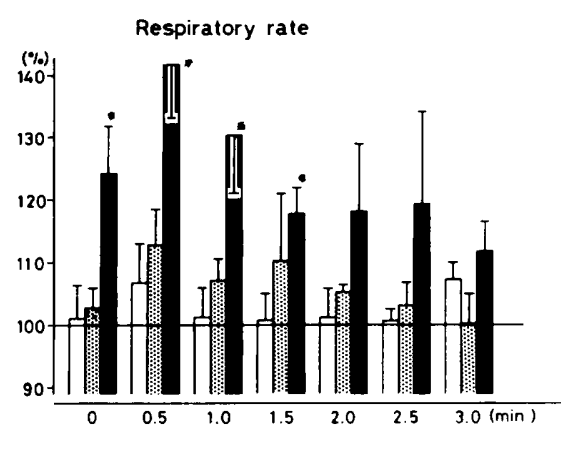

RU20201
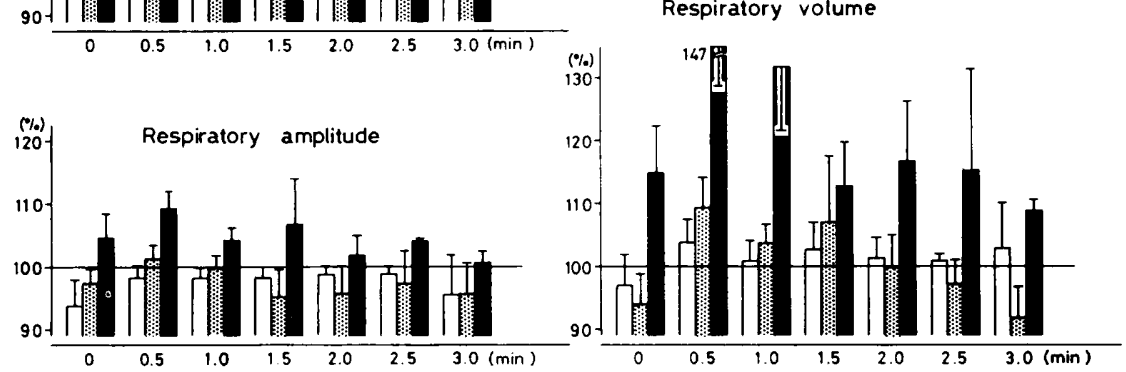

Fig. 8. The effect of RU-20201 administered intravertebroarterially on respiration in dogs. Other explanations are as in Fig. 7.

Table 2. The effects of codeine and RU-20201 given intravertebroarterially on respiration and cough reflex in dogs

\begin{tabular}{lcccccc}
\hline \multirow{2}{*}{ Drug } & Dose & \multicolumn{3}{c}{ Respiration } & \multicolumn{2}{c}{ Cough } \\
& & R.R. & R.A. & R.V. & N.C. & A.C. \\
\hline \multirow{3}{*}{ Codeine } & $0.1 \mathrm{mg}$ & - & - & - & - & - \\
& $0.3 \mathrm{mg}$ & $\downarrow$ & - & $\downarrow$ & $\downarrow \downarrow$ & - \\
& $1.0 \mathrm{mg}$ & $\downarrow \downarrow$ & - & $\downarrow \downarrow$ & $\downarrow \downarrow \downarrow$ & $\downarrow \downarrow \downarrow$ \\
\hline \multirow{3}{*}{ RU-20201 } & $1.0 \mathrm{mg}$ & - & - & - & - & - \\
& $3.0 \mathrm{mg}$ & $\uparrow$ & - & $\uparrow$ & - & - \\
& $10.0 \mathrm{mg}$ & $\uparrow \uparrow$ & - & $\uparrow \uparrow$ & - & - \\
\hline
\end{tabular}

Slight increase: $\uparrow$, Increase: $\uparrow \uparrow$, Slight decrease: $\downarrow$. Decrease: $\downarrow \downarrow$, Remarkable decrease: $\downarrow \downarrow \downarrow$

in oral administration tests by Matharu et al. (1) and Pickering and James (3). It is reported that the antitussive potency of RU-20201 is almost equal to that of codeine phosphate. RU-20201 in the form of an aerosol agent has been tested in cats and rabbits by Korpas et al. (2) and Pickering and James (3). These experiments also confirmed the antitussive effect of RU-20201. Concerning general pharmacological actions, RU-20201 has no action other than a weak local anesthetic action (12).

Based on the fact that the gastrointestinal absorption of RU-20201 is relatively greater than that of codeine phosphate $(13,14)$, we tried to compare the effects of both drugs by injecting them intravenously or intraperitoneally. In order to examine and assess their antitussive effects, in the present study, we employed the puncture electrode-induced cough (PEC) method and the chemical stimulation $\left(\mathrm{SO}_{2}\right)$ method. In the chemical stimulation method of Takagi et al., sulfur dioxide gas is obtained by adding conc. sulfuric acid to the saturated solution of sodium bisulfite. However, the procedure is rather complicated. We therefore used a simpler method employing a gas cylinder of 

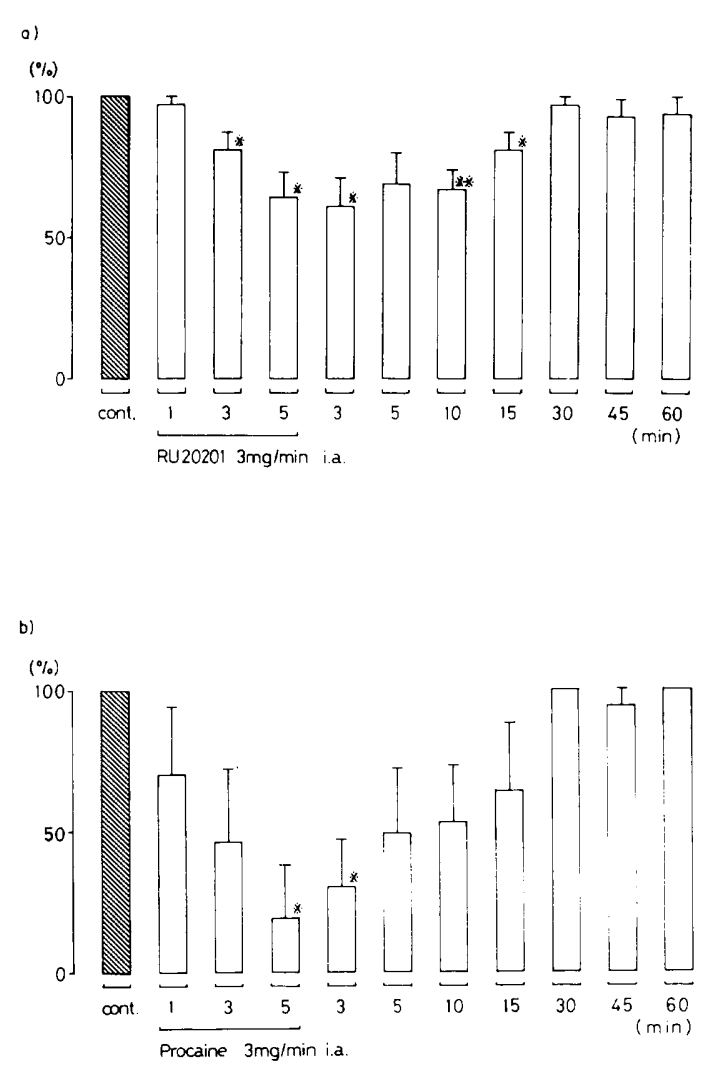

Fig. 9. The effects of a) RU-20201 and b) procaine on the cough reflex induced by electrical stimulation given to the tracheal mucosa of the dog. RU-20201 and codeine were infused close i.a. into the cranial thyroid artery in a dose of $3 \mathrm{mg} / \mathrm{min}$ for $5 \mathrm{~min}$. Each column is the mean with S.E. for five experiments. ${ }^{*} \mathrm{P}<0.05$ vs. the control response.

highly pure liquefied sulfur dioxide. In the present study, the antitussive effects of RU-20201 administered intravenously or intraperitoneally were found to be between ten to twenty times less than those of codeine phosphate in the case of dogs using the electrical stimulation method and in the case of guinea pigs, about four times less in the chemical stimulation method and about twelve times less in the electrical stimulation method. It has been reported by Matharu et al. (1), however, that RU-20201 and codeine phosphate have a practically equipotent antitussive effect in the case of oral administration. The main reason for this discrepancy seems to lie in the fact that the gastrointestinal absorption of codeine phosphate is poor as compared with RU-20201 $(13,14)$.

The arc of the cough reflex consists of the cough receptors, afferent pathway, cough center, efferent pathway and respiratory organs $(15,16)$. Theoretically, coughing can be suppressed by blocking or inhibiting this arc at any point. Yamatsu et al. and Kasé et al. (17. 18) administered some antitussive drugs through various routes including the femoral vein, common carotid artery, vertebral artery and cerebellomedullary cistern in order to disclose the central action. In the present study, the central actions of the two drugs were compared by administering them into the vertebral artery. The results with the intra-arterial administration of codeine phosphate revealed that the agent had an excellent antitussive effect, whereas no antitussive effect was found when RU-20201 was administered by the same route, even in a dose 10 times greater than that of codeine phosphate. This result therefore suggests that RU-20201 might not directly affect the cough center. This statement is also supported by the finding that the amount of RU-20201 entering the brain was considerably lower than that entering other organs when the drug was administered to rats intravenously (13).

The respiratory action of both drugs was simultaneously studied along with their antitussive one. Codeine phosphate was found to have an inhibitory effect on respiration. There is a report (12) which states that a transient stimulation of respiration was observed when RU-20201 was intravenously administered in rabbits. In the present study, a similar stimulating effect on respiration was confirmed in dogs.

Kito et al. (19) and Yanaura et al. (20) found that fominoben, one of the antitussive drugs, stimulates respiration in spite of depressing coughs. In our previous experiment (20), fominoben was administered into the vertebral artery of the dog in the same manner as in the present study. An i.a. injection of fominoben ( $3 \mathrm{mg}$ ) caused a significant but transient stimulation of respiration, and it depressed coughs by about $50 \% 1$ to 3 min after administration. RU20201 and fominoben injected intra-arterially 
have an almost equipotent stimulatory effect on respiration, but in contrast to fominoben, RU-20201 has no antitussive effect when administered by this route. The stimulating action on respiration of fominoben is considered to be based on a direct effect on the central respiratory neuronal mechanisms in the brain stem (21). The mechanism for the stimulatory effect of RU-20201 on respiration remains to be clarified.

Kasé et al. (18) were the first who described a method to clarify the peripheral (receptor site) actions of antitussive drugs. They recorded the afferent impulses from the superior laryngeal nerve that were produced by electrical stimulation of the tracheal mucosa by means of a puncture electrode. Then, they assessed the action on the receptor level by observing a quantitative change in the impulses evoked. With this method, however, the effects of the drug on other sites than cough receptors may also be involved in the change because the drug is given systemically by intravenous administraticn. In the present study, therefore, the drug was applied locally to the receptor level where electrical stimulation was given to induce coughs, enabling the peripheral action of the drug to be cbserved in the region directly (11). One of the drugs which inhibit coughing by acting on the receptor level is a local anesthetic. Yanaura (22) state that coughing is inhibited by applying procaine to the tracheal mucosa. They also mention that coughing is inhibited by injecting procaine into the anterior thyroid artery which perfuses the stimulated area (23). The same result was obtained in the present study. This means that procaine shows an antitussive effect through its action on the cough receptor level. It was observed that RU-20201 also showed an inhibitory effect on the cough response by acting on the cough receptor level, but that this effect was weaker than that of procaine. A definite local anesthetic action has not been observed with RU-20201 (12). Benzonatate is said to show an antitussive effect through its selective anesthetic action on the stretch receptors in the lung $(24,25)$. It has been confirmed by Yanaura et al. (26) that benzonatate produces its antitussive effect through the action on the stretch receptors. It has also been confirmed by Yuizono (27) that the agent decreases the number of impulses from the stretch receptors. When benzonatate is applied to the cough receptor level, however, it does not cause an antitussive effect (23) nor decreases afferent impulses from the receptors (27). Thus, an action of an antitussive drug at the cough receptor level is not necessarily explained by the local anesthetic action. It is therefore unreasonable to discuss the control of coughing only in terms of a general local anesthetic action. The mechanism of the peripheral action shown by RU-20201 has not yet been clarified. RU-20201 is, however, a very promising antitussive drug that has a different mechanism of action from those of previous and existing antitussive drugs.

Generally, antitussive drugs which work on the cough center often inhibit the respiratory center too. Clinically, however, a drug is considered to be a useful antitussive preparation if it does not inhibit respiration but in fact stimulates it. RU-20201 may be very useful from this aspect because it stimulates respiration.

\section{References}

1 Matharu, S.S., Rowlands, D.A., Taylor, J.B. and Westwood, R.: Synthesis and antitussive activity of aminotetra- (and -hexa-) hydrodibenzofurans. J. Med. Chem. 20, 197-204 (1977)

2 Korpas, J., Nosalova, G. and Widdicombe, J.G.: The anti-tussive actions of the drug RU-20201 given as an aerosol to cats. J. Pharm. Pharmacol. 30, 563-565 (1978)

3 Pickering, R.W. and James, G.W.L.: The antitussive activity of a novel compound RU-20201. Arzneimittelforsch. 29, 287-289 (1979)

4 Yanaura, S., Kitagawa, H., Hosokawa, T. and Misawa, M.: Effects of methanobenzazonine $(2,3,4,5,6,7$-hexahydro-1,6-methano- $1 \mathrm{H}-4$ -

benzazonine) derivatives on the cough reflex and respiration. Folia Pharmacol. Japon. 80, 43-50 (1982) (Abs. in English)

5 Benson, W.M., Stefko, P.L. and Randall, L.O.: Comparative pharmacology of levorphan, racemorphan and dextrorphan and related methyl ethers. J. Pharmacol. Exp. Ther. 109, 189-200 (1953)

6 Yanaura, S., Iwase, H., Sato, S. and Nishimura, T.: A new method for induction of the cough 
reflex. Japan. J. Pharmacol. 24, 453-460 (1974)

7 Takagi, K., Fukuda, H. and Yano, K.: Studies on antitussives. I. Bioassay of antitussives. Yakugaku Zasshi 80, 1497-1501 (1960) (Abs. in English)

8 Yanaura, S., Kitagawa, H., Hosokawa, T. and Misawa, M.: A new screening method for evaluating antitussives in conscious guinea pigs. J. Pharmacobiodyn. 5, 965-971 (1982)

9 Brownlee, K.A., Hodges, J.L., Jr. and Rosenblatt, M.: The up and down method with small samples. J. Am. Stat. Assoc. 48, 262-277 (1953)

10 Yanaura, S., Kitagawa, H., Hosokawa, T. and Misawa, M.: Effects of respiratory drugs on the cough reflex. Folia Pharmacol. Japon. 80, 51-59 (1982) (Abs. in English)

11 Yanaura, S., Hosokawa, T., Kitagawa, H. and Yamatake, Y.: Influence of tracheal muscular tone on the initiation of cough reflex. Japan. J. Pharmacol. 28, 447-455 (1978)

12 Pickering, R.W. and James, G.W.L.: The general pharmacology of a novel antitussive compound RU-20201. Arzneimittelforsch. 29, 642-646 (1979)

13 Daniel, J.W., James, G.W.L., Rowlands, D.A. and Taylor, J.B.: The physiological disposition of the antitussive agent, 1,2,3,4,4a,9b-hexahydro8,9b-dimethyl-4-[3-(4-methylpiperazin-1-yl) propionamido] dibenzofuran-3-one dihydrochloride (Azipranone), in man, rat, dog and baboon. Xenobiotica 8, 321-329 (1978)

14 The Pharmaceutical Codex (incorporating the British Pharmaceutical Codex). Eleventh Edition. The Department of Pharmaceutical Sciences of the Pharmaceutical Society of Great Britain. London, 215 (1979)

15 Bucher, K.: Pathophysiology and pharmacology of cough. Pharmacol. Rev. 10, 43-58 (1958)

16 Widdicombe, J.G.: Respiratory reflexes. In Handbook of Physiology, p. 585. American Physiol. Soc., Washington, D.C. (1964)

17 Yamatsu, K., Ohtsu, K., Kasé, Y., Miyata, T. and Yuizono, T.: On the site of antitussive action of 1 (2-benzylphenoxy)-2-piperidinopropane phosphate (Pirexyl). Japan. J. Pharmacol. 17, 538549 (1967)
18 Kasé, Y., Wakita, Y., Yuizono, T., Kito, G. and Kikuchi, K.: On the sites of antitussive action of $\mathrm{N}$ - (2-picolyl) - N-phenyl-N-(2-piperidinoethyl) amine (TAT-3). Arzneimittelforsch. 20, 37-43 (1970)

19 Kito, G., Kasé, Y., Yakushiji, T., Miyata, T., Okano, Y., Sato, M. and Ishihara, T.: Pharmacology of fominoben, a new antitussive possessing respiratory stimulatirig action. Pharmacometrics 8, 1491-1513 (1974) (Abs. in English)

20 Yanaura, S., Kitagawa, H., Jr., Hosokawa, T. and Misawa, M.: Difference in effects of antitussive drugs on respiration and cough reflex. Folia Pharmacol. Japon. 82, 213-222 (1983) (Abs. in English)

21 Hukuhara, T., Jr.: Effects of fominoben on the functional organization of the central respiratory neuronal mechanisms in th brain stem. Tokyo Jikeikai Med. J. 91, 236-251 (1976) (Abs. in English)

22 Yanaura, S.: Structure-activity relationship of antitussive drugs. Folia Pharmacol. Japon. 54, 688-708 (1958) (in Japanese)

23 Yanaura, S., Hosokawa, T., Kitagawa, H., Jr. and Misawa, M.: Peripheral effects of morphine and codeine on the cough reflex. Japan. J. Pharmacol. 31, 529-536 (1981)

24 Bucher, K.: Tessalon, ein hustenstillendes Mittel von neuartigem Wirkungsmechanismus. Schweiz. Med. Wochenschr. 86, 94-96 (1956)

25 Bein, H.J. and Bucher, K.: Anästhetische Wirkung an Lungendehnungsrezeptoren und aridererı nervösen Substraten (Zur Pharmakologie des Tessalon). Helv. Physiol. Acta 15, 55-62 (1957)

26 Yanaura, S., Hosokawa, T., Kitagawa, H., Jr., Kamei, J. and Misawa, M.: Effects of peripheral airway response on the cough reflex. Folia Pharmacol. Japon. 76, 709-716 (1980) (Abs. in English)

27 Yuizono, T.: On the site of antitussive actions of ethyldibunate, benzonatate and (-)-methyl ephedrine. Yakugaku Zasshi 87, 923-934 (1967) (Abs. in English) 